\title{
Prevalence, Incidence and Risk Factors for Acquisition of Herpes Simplex Virus Type 2 among Fishermen on the Shores of Lake Victoria in Kisumu County, Kenya
}

\author{
Raphael O. Ondondo ${ }^{1,2,3,4}$, Zipporah W. Ng'ang'a ${ }^{2}$, Solomon Mpoke', Michael K. Kiptoo',2, \\ Elizabeth A. Bukusi 1,2,4 \\ ${ }^{1}$ Kenya Medical Research Institute (KEMRI), Nairobi, Kenya \\ ${ }^{2}$ Jomo Kenyatta University of Agriculture and Technology, Nairobi, Kenya \\ ${ }^{3}$ Masinde Muliro University of Science and Technology, Kakamega, Kenya \\ ${ }^{4} \mathrm{KEMRI}$ in Collaboration with University of California San Francisco, San Francisco, USA \\ Email: raphondondo@gmail.com
}

Received 21 April 2014; revised 21 May 2014; accepted 30 May 2014

Copyright (C) 2014 by authors and Scientific Research Publishing Inc.

This work is licensed under the Creative Commons Attribution International License (CC BY). http://creativecommons.org/licenses/by/4.0/

(c) (i) Open Access

\section{Abstract}

Background: Herpes simplex virus Type 2 (HSV-2) has been associated with HIV infection. More recently, HSV-2 incidence has been linked to HIV acquisition. A few studies have suggested that the fishing communities have a high HSV-2 prevalence but there is limited knowledge on HSV-2 incidence and associated risk factors among fishermen. Methods: Three hundred fishermen were consented, and evaluated for baseline HSV-2 serology status and again after 12 months among those negative at baseline. Sexual behavior and socio-demographic data were collected at enrolment and exit visits using a structured questionnaire. Baseline HIV serology and Human papillomavirus (HPV) DNA genotyping were also performed. Multivariate logistic regression was used to determine independent factors associated with HSV-2 acquisition. Results: Baseline HSV-2 prevalence was $56.3 \%$ (95\% CI: 50.7 - 62.0). Factors associated with HSV-2 prevalence were, older age (aOR = 1.96; 95\% CI: 1.16 - 2.85), history of STI (aOR 2.12; 95\% CI: 1.19 - 3.91), infection with HIV (aOR 2.22; 95\% CI: 1.17 - 4.22), ever married (aOR = 3.80; 95\% CI: 1.42 - 11.90), most recent sexual act with sex worker/casual partner (OR=3.56; 95\% CI: 1.49 - 8.62) and inconsistent condom use with new sexual partner ( $\mathrm{aOR}=6.34 ; 95 \%$ CI: $2.24-13.04)$. The HSV-2 incidence was 23.6 $(95 \% \mathrm{CI}=15.4-31.8) / 100$ pyr. Infection with persistent high-risk (HR) HPV (aIRR $=3.35 ; 95 \% \mathrm{CI}$ : 1.21 - 11.37), multiple ( $\geq 2)$ partners in 12 months prior to study participation (aIRR $=4.77 ; 95 \%$ CI: 1.12 - 11.38), inconsistent condom use with new partner ( $\operatorname{aIRR}=2.53$; 95\% CI: $1.12-7.38$ ) and most recent sexual act with sex worker/casual partner $(O R=3.03 ; 95 \%$ CI: $1.17-8.58)$ were independent risk factors for HSV-2 acquisition. Conclusion: The incidence of HSV-2 is very high 
among fishermen. It is associated with persistent HR HPV infection and high-risk sexual behavior. Intervention strategies targeting these men with high risk sexual behavior are urgently needed to stop new HSV-2 acquisition and subsequently prevent HIV infection.

\author{
Keywords
}

Fishermen, Risk Factors, HSV-2 Incidence, HSV-2 Prevalence, HPV, HIV

\title{
1. Introduction
}

Genital ulcer disease (GUD) is clearly associated with increased risk of HIV acquisition and transmission. The genital ulcerations facilitate increased shedding and easier entry of HIV into the host [1]-[3]. Therefore, it is biologically plausible that presence of herpetic lesions would increase the risk of HIV acquisition. Herpes simplex virus type-2 (HSV-2) is one of the most prevalent sexually transmitted infections worldwide and the important leading cause of GUD ahead of syphilis and chancroid [4]-[6]. Epidemiological studies have established a strong association between prevalent HSV-2 and incident HIV infection [7]-[14]. Recent studies further suggest that incident HSV-2 infection increases the risk for new HIV infection [10] [12] [14]-[16]. In summary, underlying HSV-2 infection substantially elevates the risk of incident HIV infection. Therefore, prevalent and incident HSV-2 infection is indicated as a significant risk factor or co-factor for new HIV acquisition.

Fishing communities are composed of a sub-population of men and women with high-risk sexual behavior [17] biologically demonstrated by high HIV and/or HSV-2 prevalence [18]-[22]. Moreover, HIV incident rates are reportedly much higher among fishing communities than in the general population [23]. Although previous studies have evaluated risk factors for incident HSV-2 infection among individuals with high-risk sexual behavior [7] [14] [15] [24], there is limited knowledge on HSV-2 incidence among fishing communities in Sub-Saharan Africa; the epicenter of the HIV epidemic. Knowledge of HSV-2 acquisition risk factors is needed in the design of targeted interventions to limit incident HSV-2 infection and potentially lowering rates of new HIV infection. In this study, we report the results of the first study to evaluate the incidence and risk factors for HSV-2 infection among fishermen on the shores of Lake Victoria, Kisumu, Kenya.

\section{Methods}

\subsection{Study Design and Clinical Procedures}

Between September and December 2011, fishermen along beaches on the Kenyan side of Lake Victoria in Kisumu County were consented into a prospective study evaluating risk factors for HSV-2 acquisition. Sexually active fishermen aged 18 - 47 years were eligible for the one year study whose follow-up was concluded in December 2012. Blood samples for HSV-2 serologic testing were collected at baseline and after 12 months of follow-up for incidence rate among men negative for HSV-2 at baseline. Genital examination for clinical STIs and collection of genital swabs (from the glans, head, shaft, scrotum and perineum) for human papillomavirus (HPV) testing was performed at an interval of 3 months for the entire study period. Baseline HIV and HPV genotype status were determined as part of potential background risk factors for HSV-2 infection. Data on socio-demographic characteristics and sexual risk behavior was collected through interviewer administered structured questionnaire at enrollment and at study exit (month 12). Kenya Medical Research Institutes Scientific and Ethical Review Committees provided ethical clearance for the study protocol (SSC No.2014).

\subsection{Laboratory Detection of HSV-2, HIV and HPV}

HSV-2 infection was determined by HSV-2 enzyme-linked immunosorbent assay (ELISA) (Kalon Biological Ltd, Guilford, UK), as per the manufacturer's instructions. Men negative for HSV-2 serology were evaluated for HSV-2 incidence at the end of 12 month study follow-up. HIV status was determined using two rapid screening tests in parallel and confirmed by two separate ELISA tests. Determine (ABBOTT Laboratories, Diagnostic division, Chicago IL, USA) and UniGold HIV 1/2 rapid kit (Trinity Biotech, Ireland USA) with all concordant HIV positive or HIV discordant results confirmed by enzyme immunoassays: Vironostika ELISA (BioMerieux- 
Vironostika HIV Uni-Form II plus O Antigen/Antibody ELISA, Marcy l'Etoile, France) and Murex HIV 1/2 Combo (Murex Biotech Limited, Dartford, UK). HPV infection was determined by polymerase chain reaction (PCR) using PGMY11/09 primer set and detection by genotype-specific probes multiplex Luminex assay for 33 important genital HPV genotypes; high-risk (HR) HPV genotypes: 16,18,26,31,33,35,39,45,51,52,53,55,56,58, 59,66,68,73,82,83 and low-risk (LR) HPV genotypes: 6,11,40,42,54,61,62,67,70,72,81,84, CP6108. Persistent HPV infection defined as detection of the same genotype at two consecutive visits $\geq 6$ months apart was determined at subsequent visits.

\subsection{Statistical Analysis}

HSV-2 incidence rate and person-time calculations were performed with the assumption that HSV-2 infection occurred at any time between baseline HSV-2 negative serologic test and study exit (after 12 months) positive serological test. HSV-2 incidence was estimated per 100 person-years (pyr). For HSV-2 prevalence analyses, associations with fixed covariates such as age, marital status, and HPV/HIV status at enrollment, as well as sexual risk behavior (number of sexual partners, sexual relationships and condom use) reported at baseline and exit of the study during were determined by chi square, logistic regression and Fisher's exact for smaller numbers $(\leq 6)$. Risk factors with a $P$ value less than 0.10 in bivariate logistic regression were entered into a multivariate multiple logistic regression model to estimate adjusted measures of association for HSV-2 prevalence (aOR) and incidence rate ratio (aIRR) at 95\% confidence interval (95\% CI) for HSV-2 acquisition. SPSS version 19 (SPSS, Chicago, IL) and Stataversion 12 (StataCorp LP 4905 Lakeway Drive College Station, Texas 77845 USA) were used.

\section{Results}

Of the 300 fishermen that were enrolled between September 2011 and December 2012, 254 (85\%) returned for the scheduled annual exit visit. Enrolled men had median (IQR) age of 26.5 (21 - 32), median (IQR) 8 (5 - 15) number of sexual partners lifetime, and $2(1-3)$ one year prior to study participation. The majority (91\%) earned $\leq$ KShs 10,000 (110 USD)/month and only 24\% were circumcised (Table 1). All men with baseline and study exit HSV-2 serology data were included in this study. At baseline, 169 men were detected with HSV-2. Of the 131 men who were negative for HSV-2 at baseline, 106 (81\%) retuned for their exit visit and were significantly younger mean (SD) age 25.8 (5.84) years compared to men infected with HSV-2 at baseline (mean age 29.3, SD \pm 6.37 ).

Baseline HSV-2 prevalence was 56.3\% (95\% CI: 50.7 - 62.0). Persons with prevalent HSV-2 infection were more likely to be older (>28 years old) (70\% vs. $49 \%$ ), married (62\% vs. $34 \%$ ), HIV-1 positive (76\% vs. 50\%), ever had an STI (71\% vs. 51.1\%) and co-infected with HPV (62\% vs. 50\%) as shown in Table 1. Bivariate analysis revealed that older age (OR, 2.41; 95\% CI, 1.42 - 4.11), ever married (OR, 2.13; 95\% CI, 1.02 - 4.93), HIV infection (OR, 3.06; 95\% CI, 1.67 - 5.61), HPV infection (OR, 1.64; 95\% CI, 1.03 - 2.60), history of STI (OR, 2.41; 95\% CI, 1.38 - 4.22) and lack of condom use (OR, 5.31; 95\% CI, 2.29 - 12.33) were associated with HSV-2 prevalence. Additionally, among married fishermen, most recent sexual act with partner other than the wife was associated with increased odds of HSV-2 infection; girlfriend (OR, 2.58; 95\% CI, 1.17 - 5.71) or casual partner/sex worker (OR, 3.56; 95\% CI, 1.49 - 8.62). On the multivariate model, lack of condom use (aOR, 6.34; 95\% CI, 2.24 - 13.04), HIV-1 positive (aOR, 2.22; 95\% CI, 1.17 - 4.22), and history of STI (aOR, 2.12; 95\% CI, 1.19 - 3.91) were independently associated with HSV-2 prevalence (Table 2). Among men with baseline HSV-2 infection, 93 (55\%) were positive for HPV DNA, of which 70 (75\%) were at least infected with a HR HPV genotype. Similar HPV proportions were observed among HSV-2 negative men; 75\% (42/56) of HPV positive men had at least one HR HPV genotype. Baseline HPV infection was not associated with HSV-2 prevalence (Table 2).

Among the 131 men negative for HSV-2 at baseline, 106 had exit data and 25 (23.6\%) incident cases were identified during the one year follow-up period. This resulted in an incidence rate of 23.6 cases/100 pyr. Incidence rates were higher among men with a history of STI ( 25.0 vs 23.3/100 pyr), positive for HIV (28.6vs 22.8/100 pyr), HPV infection (31.9 vs 16.9/100 pyr), those whose most recent sexual act was with a casual partner/sex worker (44.8 vs 15.6/100 pyr)and those with multiple sexual partners in the last 6 months (31.3 vs. 17.2/100 pyr), 12 months, (33.3 vs. 9.3/100 pyr), and >5 sexual partners lifetime (31.3 vs. 10.3/100 pyr). The incidence rate was much lower among men not engaging in transactional sex (3.8 vs 30.0/100 pyr) and those who 
Table 1. Baseline viral STI and socio-demographic characteristics of fishermen in the study.

\begin{tabular}{|c|c|c|c|}
\hline Characteristic & All $(N=300)$ & HSV-2 Positive (n = 169) & HSV-2 Negative $(n=131)$ \\
\hline Age: Mean (SD) & $27.7(6.40)$ & $29.3(6.37)$ & $25.8(5.84)$ \\
\hline 18 - 28 years & 194 & $95(49.0)$ & $99(75.6)$ \\
\hline 29 - 47 years & 106 & $74(68.9)$ & $32(24.4)$ \\
\hline \multicolumn{4}{|l|}{ Marital status: } \\
\hline Single & 64 & $22(34.4)$ & $42(32.1)$ \\
\hline Ever married & 236 & 147 (62.3) & 89 (67.9) \\
\hline \multicolumn{4}{|l|}{ Circumcised: } \\
\hline Yes & 72 & $36(50.0)$ & $36(27.5)$ \\
\hline No & 228 & $133(58.0)$ & 95 (72.5) \\
\hline \multicolumn{4}{|l|}{ Sexual partners in last 12 months: } \\
\hline$<2$ partner & 112 & $65(58.0)$ & 47 (35.9) \\
\hline$\geq 2$ partners & 188 & $104(55.3)$ & $84(64.1)$ \\
\hline \multicolumn{4}{|l|}{ Sexual partners lifetime: } \\
\hline$\leq 5$ partners & 108 & $59(54.6)$ & $49(37.4)$ \\
\hline$>5$ partners & 192 & $110(57.3)$ & $82(62.6)$ \\
\hline \multicolumn{4}{|l|}{ Engaged in transactional sex: } \\
\hline Yes & 34 & $14(41.1)$ & $20(15.3)$ \\
\hline No & 266 & $155(58.3)$ & $111(84.7)$ \\
\hline \multicolumn{4}{|l|}{ Baseline HIV status: } \\
\hline Negative & 230 & $116(50.4)$ & $114(87.0)$ \\
\hline Positive & 70 & $53(75.7)$ & $17(13.0)$ \\
\hline \multicolumn{4}{|l|}{ Baseline HPV status: } \\
\hline Negative & 151 & $76(50.1)$ & 75 (57.3) \\
\hline Positive & 149 & $93(62.4)$ & $56(42.7)$ \\
\hline \multicolumn{4}{|l|}{ Kind of partner for recent sexual act: } \\
\hline Single men: & $(\mathrm{N}=69)$ & $(n=24)$ & $(\mathrm{N}=45)$ \\
\hline Girlfriend (regular partner) & 51 & 19 (37.3) & $32(71.1)$ \\
\hline Casual partner/sex worker & 18 & $5(27.8)$ & 13 (28.9) \\
\hline Married men: & $(\mathrm{N}=231)$ & $(\mathrm{n}=145)$ & $(\mathrm{n}=86)$ \\
\hline Wife & 41 & $17(41.5)$ & $24(27.9)$ \\
\hline Girlfriend & 116 & $75(64.7)$ & $41(47.7)$ \\
\hline Casual partner/sex worker & 74 & $53(71.6)$ & $21(24.4)$ \\
\hline \multicolumn{4}{|l|}{ Used condom in recent sexual act: } \\
\hline Yes & 42 & $18(42.9)$ & $24(18.3)$ \\
\hline No & 258 & $151(58.5)$ & $107(81.7)$ \\
\hline \multicolumn{4}{|l|}{ Condom use with new partner: } \\
\hline Most of the time (>75\%) & 107 & $65(60.7)$ & $42(32.1)$ \\
\hline Some of the time ( $25 \%$ - $75 \%)$ & 65 & $49(75.4)$ & $16(12.2)$ \\
\hline Rarely $(<25 \%)$ & 128 & $55(43.0)$ & $73(55.7)$ \\
\hline \multicolumn{4}{|l|}{ Ever had STI: } \\
\hline No & 223 & $114(51.1)$ & 109 (83.2) \\
\hline Yes & 77 & 55 (71.4) & 22 (16.8) \\
\hline
\end{tabular}


Table 2. Factors associated with baseline HSV-2 infection among fishermen.

\begin{tabular}{|c|c|c|c|c|}
\hline Characteristic & OR (95\% CI) & P-value & aOR (95\% CI) & P-value \\
\hline \multicolumn{5}{|l|}{ Age: } \\
\hline 18 - 28 years & Reference & & Reference & \\
\hline 29 - 47 years & $2.41(1.42-4.11)$ & $<0.001$ & $1.96(1.16-2.85)$ & 0.003 \\
\hline \multicolumn{5}{|l|}{ Marital status : } \\
\hline Single & Reference & & Reference & \\
\hline Ever married & $2.13(1.02-4.93)$ & $<0.001$ & $3.80(1.42-11.90)$ & 0.001 \\
\hline \multicolumn{5}{|l|}{ Circumcised: } \\
\hline Yes & Reference & & Not included & \\
\hline No & $1.40(0.82-2.38)$ & 0.215 & & \\
\hline \multicolumn{5}{|l|}{ Sexual partners in last 12 months: } \\
\hline$<2$ partner & Reference & & Not included & \\
\hline$\geq 2$ partners & $0.90(0.54-1.48)$ & 0.646 & & \\
\hline \multicolumn{5}{|l|}{ Lifetime Sexual partners: } \\
\hline$\leq 5$ partners & Reference & & Not included & \\
\hline$>5$ partners & $1.11(0.67-1.84)$ & 0.655 & & \\
\hline \multicolumn{5}{|l|}{ Engaged in transactional sex: } \\
\hline Yes & Reference & & Reference & \\
\hline No & $0.50(0.24-1.04)$ & 0.062 & $0.56(0.28-1.33)$ & 0.189 \\
\hline \multicolumn{5}{|l|}{ Baseline HIV status: } \\
\hline Negative & Reference & & Reference & \\
\hline Positive & $3.06(1.67-5.61)$ & $<0.001$ & $2.22(1.17-4.22)$ & 0.015 \\
\hline \multicolumn{5}{|l|}{ Baseline HPV status: } \\
\hline Negative & Reference & & Reference & \\
\hline Positive & $1.64(1.03-2.60)$ & 0.035 & $1.36(0.78-2.37)$ & 0.283 \\
\hline \multicolumn{5}{|l|}{ Partner in recent sexual act: } \\
\hline \multicolumn{5}{|l|}{ Single men: } \\
\hline Girlfriend (regular) & Reference & & Not included & \\
\hline Casual partner/sex worker & $1.54(0.42-5.92)$ & 0.468 & & \\
\hline \multicolumn{5}{|l|}{ Married men: } \\
\hline Wife & Reference & & Not included & \\
\hline Girlfriend & $2.58(1.17-5.71)$ & 0.009 & & \\
\hline Casual partner/sex worker & $3.56(1.49-8.62)$ & 0.001 & & \\
\hline \multicolumn{5}{|l|}{ Condom use in recent sexual act: } \\
\hline Yes & Reference & & Reference & \\
\hline No & $1.88(0.97-3.64)$ & 0.06 & $1.06(0.48-2.34)$ & 0.885 \\
\hline \multicolumn{5}{|l|}{ Condom use with new partner: } \\
\hline Most of the time ( $>75 \%)$ & $0.45(0.26-0.78)$ & 0.005 & Reference & \\
\hline Rarely (<25\%) & $5.31(2.29-12.33)$ & $<0.001$ & $6.34(2.24-13.04)$ & 0.001 \\
\hline Some of the time (25\% - 75\%) & $2.03(0.76-5.38)$ & 0.155 & & \\
\hline \multicolumn{5}{|l|}{ Ever had STI: } \\
\hline No & Reference & & Reference & \\
\hline Yes & $2.41(1.38-4.22)$ & 0.002 & $2.12(1.19-3.91)$ & 0.014 \\
\hline
\end{tabular}


reported condom use on the last sexual act (7.1 vs 33.3/100 pyr) or with new sexual partner (14.5 vs 36.4/100 pyr) as shown in Table 3. Bivariate analysis revealed that the number of sexual partners in the last 12 months (IRR, 3.58; 95\% CI, 1.32 - 9.71), number of lifetime sexual partners (IRR, 3.06; 95\% CI, 1.13 - 8.26) and most recent sexual act with casual partner/sex worker (IRR, 4.40; 95\% CI, 1.53 - 12.82) were associated with HSV-2 incidence. Condom use with new sexual partner (IRR, 0.30; 95\% CI, 0.10 - 0.83) and lack of transactional sex (IRR, 0.09; 95\% CI, 0.01 - 0.71) were protective against incident HSV-2 infection. In multivariate analysis, lack of condom use with new sexual partner (aIRR, 2.53; 95\% CI, 1.12 - 7.38), no transactional sex (aIRR, 0.15; 95\% CI, 0.08 - 0.95), multiple sexual partners in the last 12 months (aIRR, 4.77; 95\% CI, 1.12 - 11.38) and most recent sexual act with casual partner/sex worker (aIRR, 3.03; 95\% CI, 1.17 - 8.58) remained significantly associated with incident HSV-2 infection (Table 3).

Of the 25 cases with incident HSV-2 infection, 15 (60.0\%) were infected with persistent HR HPV genotypes compared to $29.6 \%$ (24/81) among men who remained HSV-2 negative at study exit. Therefore men with persistent HR HPV infection were 3.6 times more likely to acquire new HSV-2 infection compared to those without (aIRR, 3.35; 95\% CI, 1.21 - 11.37). However, baseline HIV infection and exclusive infection with persistent LR HPV genotypes were not associated with HSV-2 incidence (Table 3). Among 92 men eligible for incidence evaluation for both HIV and HSV-2, 3 of 5 men with new HIV infection had incident HSV-2 infection compared to 18 of 87 men without new HIV infection. Therefore, men with new HSV-2 infection were 5 times more likely to acquire new HIV infection (IRR, 5.07; 95\% CI, 0.91 - 28.37) compared to those without. However, the association between incident HSV-2 infection and HIV acquisition was on the borderline $(\mathrm{P}=0.076)$.

\section{Discussion}

Fishermen in this study had a high burden of HSV-2 infection. The estimated baseline HSV-2 prevalence of $56 \%$ is over two times higher than the estimated HSV-2 prevalence of $26.3 \%$ for men drawn from the general national adult population in Kenya [25] [26], 26.5\% among young men in Kisumu Kenya [16], 22\% among high risk men for HIV in Mombasa, Kenya [15] and 20.3\% among MSM in the US [13]. Similar high prevalence (43\% - 80\%) was previously observed among fishermen along Lake Victoria in Kenya [23], among patients attending STD clinic in India [10], among women at high risk for HIV infection in Mozambique [27] and among female sex workers in Mombasa, Kenya [15] [24]. Risk factors for prevalent HSV-2 infection (Table 2) found in this study (older age, marital status, inconsistent condom use, history of STI, and HIV infection) were consistent with results from other studies [10] [15] [23] [24].

The HSV-2 incidence rate of 23.6/100 pyr observed in this study, to our knowledge is the highest for HSV-2 among men observed anywhere in the world. Similar HSV-2 incident rates have only been documented among women with high risk sexual behavior. These studies found HSV-2 incidence rate of 23/100 pyr among female sex workers in Mombasa, Kenya [24], 21.9/100 pyr among female sex workers in China [28] 22.1/100pyr among women at high risk for HIV infection in Mombasa, Kenya [15] and 20.5/100 pyr among women with high risk sexual behavior in Beira, Mozambique [27]. HSV-2 incidence of 11.4/100 pyr was shown among patients attending STD clinic in India [10] and 9.0/100 pyr found among men at high risk for HIV infection in Mombasa, Kenya [15].

The rate of new HSV-2 infection in this study was almost 3-5 times that observed (4.9 - 7.4 /100 pyr) in studies evaluating HSV-2 incidence among young men drawn from the general population (in Kenya and Uganda) [16] [29], and adolescents in the US [30]. Additionally, this study found much higher HSV-2 incidence rate compared to 2.4/100 pyr (with HIV negative partner) - 5.0/100 pyr (with HIV positive partner) for all anal intercourse observed among MSM in the US [13] and 4.0/100 pyr among injection drug users (IDU) in Chiang Mai, Thailand [31].

In this study, engagement in transactional sex had a borderline association $(\mathrm{P}=0.047)$ with HSV-2 incidence, although the majority of fishermen reported recent transactional sexual activity. Transactional sex as a risk for HSV-2 acquisition was also observed in other studies [10] [25]. Moreover, recent sex with casual partners, multiple sexual partners and inconsistent condom use; found to be independently associated with HSV-2 incidence in this study, were also demonstrated elsewhere [10] [13] [27] [30]. A greater ( $\geq 3$ ) number of sexual partners in the 12 months prior to study participation was a stronger risk factor for HSV-2 acquisition compared to higher ( $\geq 6)$ number of sexual partners lifetime (Table 3). Similarly, Brown et al. (2006) found an increased risk of HSV-2 acquisition strongly associated with a higher number of sexual partners $(\geq 6)$ and multiple $(\geq 5)$ unprotected sexual acts, six months prior to study participation [13]. This emphasized that it is not just a temporary 
sequence of events cumulated in a lifetime but rather the intensity of high-risk sexual events occurring in the period immediately preceding HSV-2 seroconversion.

Table 3. Factors associated with incident HSV-2 infection among fishermen.

\begin{tabular}{|c|c|c|c|c|c|c|}
\hline Characteristic & $\mathbf{n}$ & Incidence (\%) & IRR (95\% CI) & P-value & aIRR (95\% CI) & P-value \\
\hline \multicolumn{7}{|l|}{ Age: } \\
\hline 26 - 47 years & 50 & $11(22.0)$ & Reference & & & \\
\hline 18 - 25 years & 56 & $14(25.0)$ & $1.14(0.57-2.27)$ & 0.716 & Not included & \\
\hline \multicolumn{7}{|l|}{ Marital status: } \\
\hline Ever married & 77 & $18(23.4)$ & Reference & & & \\
\hline single & 29 & 7 (27.4) & $1.03(0.48-2.21)$ & 0.934 & Not included & \\
\hline \multicolumn{7}{|l|}{ Circumcised: } \\
\hline No & 77 & $19(24.7)$ & Reference & & & \\
\hline Yes & 29 & $6(20.7)$ & $0.84(0.37-1.89)$ & 0.667 & Not included & \\
\hline \multicolumn{7}{|l|}{ Sexual partners in 12 months: } \\
\hline$<2$ partner & 43 & $4(9.3)$ & $0.28(0.10-0.76)$ & 0.004 & Reference & \\
\hline$\geq 2$ partners & 63 & $21(33.3)$ & $3.58(1.32-9.71)$ & 0.004 & $4.77(1.12-11.28)$ & 0.009 \\
\hline \multicolumn{7}{|l|}{ Sexual partners in lifetime: } \\
\hline$\leq 5$ partners & 39 & $4(10.3)$ & Reference & & & \\
\hline$>5$ partners & 67 & $21(31.3)$ & $3.06(1.13-8.26)$ & 0.014 & $3.76(0.86-9.15)$ & 0.089 \\
\hline \multicolumn{7}{|l|}{ Transactional sex: } \\
\hline Yes & 80 & $24(30.0)$ & Reference & & Reference & \\
\hline No & 26 & $1(3.8)$ & $0.09(0.00-0.71)$ & 0.006 & $0.15(0.08-0.95)$ & 0.047 \\
\hline \multicolumn{7}{|l|}{ Most recent sexual partner: } \\
\hline Wife/regular girlfriend & 77 & $12(15.6)$ & $0.05(0.00-0.39)$ & 0.002 & Reference & \\
\hline Casual partner/Sex worker & 29 & $13(44.8)$ & $4.40(1.53-12.82)$ & 0.002 & $3.03(1.17-8.58)$ & 0.012 \\
\hline \multicolumn{7}{|l|}{ Condom use with new partner: } \\
\hline$\geq 50 \%$ of the time & 62 & $9(14.5)$ & $0.30(0.10-0.83)$ & 0.009 & Reference & \\
\hline$<50 \%$ of the time & 44 & $16(36.4)$ & $3.37(1.21-9.56)$ & 0.009 & $2.53(1.12-7.38)$ & 0.021 \\
\hline \multicolumn{7}{|l|}{ Ever use of Condom: } \\
\hline Ever used condom & 84 & $17(20.2)$ & Reference & & & \\
\hline Never used condom & 22 & $8(36.4)$ & $0.44(0.14-1.38)$ & 0.113 & Not included & \\
\hline \multicolumn{7}{|l|}{ History of STI: } \\
\hline No & 90 & $21(23.3)$ & Reference & & & \\
\hline Yes & 16 & $4(25.0)$ & $1.10(0.26-4.23)$ & 0.885 & Not included & \\
\hline \multicolumn{7}{|l|}{ Baseline HIV: } \\
\hline Negative & 92 & $21(22.8)$ & Reference & & & \\
\hline Positive & 14 & $4(28.6)$ & $1.35(0.32-5.40)$ & 0.637 & Not included & \\
\hline \multicolumn{7}{|l|}{ Persistent all HPV: } \\
\hline Negative & 51 & $8(15.6)$ & Reference & & Reference & \\
\hline Positive & 59 & 17 (28.8) & $2.4(0.85-6.92)$ & 0.065 & $1.12(0.37-3.41)$ & 0.844 \\
\hline \multicolumn{7}{|l|}{ Persistent HR HPV: } \\
\hline Negative & 67 & $10(14.9)$ & Reference & & Reference & \\
\hline Positive & 39 & 15 (38.5) & $3.56(1.28-10.06)$ & 0.006 & $3.35(1.21$ - 11.37) & 0.009 \\
\hline \multicolumn{7}{|l|}{ Persistent LR HPV: } \\
\hline Negative & 63 & $13(20.6)$ & Reference & & & \\
\hline Positive & 43 & $12(27.9)$ & $1.49(0.55-4.03)$ & 0.387 & Not included & \\
\hline
\end{tabular}


To our knowledge, this is the first study to assess HPV infection as a risk factor for incident HSV-2 infection. Therefore, the observed association between persistent HR HPV and new HSV-2 infection warrant further studies and should be interpreted with caution. However, several studies have found that HPV infection increases the risk for HIV acquisition by 1.8 - 3.5 times [32]-[34]. Lissouba et al. (2013) in their meta-analysis review found that HR HPV infection was associated with almost a 2-fold increased risk for incident HIV infection, while LR HPV infection had only a borderline association [35]. Hypothetically, persistent HR HPV infection is biologically necessary for development of HPV disease that may be associated with breach of epithelial membranes and infiltration with pro-inflammatory cytokines and other immune cells. These potentially provide an enabling environment for HSV-2 or HIV entry and replication. Just like HSV-2, HPV is believed to be more infectious than HIV, with prevalence always exceeding that of HIV and the most infectious of the three viruses [36]. Therefore, if the interaction between HSV-2 and HPV found in this study is confirmed by other studies, HPV vaccination would be a recommended strategy for HSV-2 prevention in addition to safer sexual practices.

HSV-2 and HIV have a common route for transmission and therefore possibly share common factors onhigh-risk sexual behavior. Numerous prevalence studies have shown a strong association between the two sexually transmitted viral infections [37]. Several incidence studies have found prevalent (baseline) HSV-2 infection an important risk factor for new HIV acquisition, with the strongest association emerging between HIV incident and recent or incident HSV-2 infection [10] [12] [13] [15] [38]. In these studies, the majority of incident HSV-2 infection events occurred concurrently with or close to the HIV seroconversion events. Therefore, the high HSV-2 incidence rate observed in our current study is likely a strong biological indicator for a rapidly growing HIV epidemic in this population.

This study had some limitations. Evaluation of the independent role of incident HSV-2 infection on HIV acquisition was limited by the study power, resulting from the small numbers of HIV serocoversion events observed in this study. Additionally, the incidence of these two infections was determined at the end of the study and therefore we could not establish whether HSV-2 incident infection preceded HIV acquisition.

\section{Conclusion}

Fishermen are highly burdened and at increased risk for HSV-2 infection characterized by the highest incidence rate ever reported among men, but only comparable to rates documented among female sex workers. Persistent HR HPV infection was independently associated with increased risk for HSV-2 acquisition in addition to factors related to high risk sexual behavior. Without an efficacious HSV-2 vaccine in sight, well-tailored intervention programs promoting safer sex for prevention of HSV-2, HPV and subsequently HIV infections are urgently needed.

\section{Acknowledgements}

We gratefully acknowledge the study participants and the Beach Management Units on the study beaches for their commitment and cooperation during this study. We feel indebted to all the research assistants who worked tirelessly in the field successfully implementing this study. We sincerely appreciate the Director KEMRI and the Director Centre for Microbiology Research (CMR) KEMRI for their unwavering institutional support. This study was fully funded by the Consortium for National Health Research (CNHR) Kenya, Research Leadership Grant (RLG) 026/2009.

\section{Conflict of Interest}

The authors declare that there is no conflict of interests regarding the publication of this paper.

\section{References}

[1] Dickerson, M.C., Johnston, J., Delea, T.E., et al. (1996) The Causal Role for Genital Ulcer Disease as a Risk Factor for Transmission of Human Immunodeficiency Virus. An application of the Bradford Hill Criteria. Sexually Transmitted Diseases, 23, 429-440. http://dx.doi.org/10.1097/00007435-199609000-00015

[2] Schacker, T., Ryncarz, A.J., Goddard, J., Diem, K., Shaughnessy, M. and Corey, L. (1998) Frequent Recovery of HIV-1 from Genital Herpes Simplex Virus Lesions in HIV-1-infected men. JAMA, 280, 61-66. http://dx.doi.org/10.1001/jama.280.1.61 
[3] O’Farrell, N., Moodley, P. and Sturm, A.W. (2007) Genital Herpes in Africa: Time to Rethink Treatment. Lancet, 370, 2164-2166. http://dx.doi.org/10.1016/S0140-6736(07)61910-2

[4] Mertz, K.J., Trees, D., Levine, W.C., et al. (1998) Etiology of Genital Ulcers and Prevalence of Human Immunodeficiency Virus Coinfection in 10 US Cities. The Genital Ulcer Disease Surveillance Group. The Journal of Infectious Diseases, 178, 1795-1798. http://dx.doi.org/10.1086/314502

[5] Paz-Bailey, G., Ramaswamy, M., Hawkes, S.J. and Geretti, A.M. (2007) Herpes Simplex Virus Type 2: Epidemiologyand Management Options in Developing Countries. Sexually Transmitted Infections, 83, 16-22. http://dx.doi.org/10.1086/314502

[6] Looker, K.J., Garnett, G.P. and Schmid, G.P. (2008) An Estimate of the Global Prevalence and Incidence of Herpes Simplex Virus Type 2 Infection. Bulletin of the World Health Organization, 86, 805-812. http://dx.doi.org/10.2471/BLT.07.046128

[7] Tassiopoulos, K.K., Seage 3rd, G., Sam, N., et al. (2007) Predictors of Herpes Simplex Virus Type 2 Prevalence and Incidence among Bar and Hotel Workers in Moshi, Tanzania. The Journal of Infectious Diseases, 195, 493-501. http://dx.doi.org/10.1086/510537

[8] del Mar Pujades Rodriguez, M., Obasi, A., Mosha, F., et al. (2002) Herpes Simplex Virus Type 2 Infection Increases HIV Incidence: A Prospective Study in Rural Tanzania. AIDS, 16, 451-462. http://dx.doi.org/10.1097/00002030-200202150-00018

[9] Delany-Moretlwe, S., Lingappa, J.R. and Celum, C. (2009) New Insights on Interactions between HIV-1 and HSV-2. Current Infectious Disease Reports, 11, 135-142. http://dx.doi.org/10.1097/00002030-200202150-00018

[10] Reynolds, S.J., Risbud, A.R., Shepherd, M.E., et al. (2003) Recent Herpes Simplex Virus Type 2 Infection and the Risk of Human Immunodeficiency Virus Type 1 Acquisition in India. The Journal of Infectious Diseases, 187, 15131521. http://dx.doi.org/10.1086/368357

[11] Aaron, A.R.T., Victor, S., Godfrey, K., Amy, E.O., et al. (2009) Incident HIV and Herpes Simplex Virus Type 2 Infection among Men in Rakai, Uganda. AIDS, 23, 1589-1594. http://dx.doi.org/10.1097/QAD.0b013e32832d4042

[12] Sobngwi-Tambekou, J., Taljaard, D., Lissouba, P., Zarca, K., et al. (2009) Effect of HSV-2 Serostatus on Acquisition of HIV by Young Men: Results of a Longitudinal Study in Orange Farm, South Africa. The Journal of Infectious Diseases, 199, 958-964. http://dx.doi.org/10.1086/597208

[13] Brown, E.L., Wald, A., Hughes, J.P., Morrow, R.A., et al. (2006) High Risk of Human Immunodeficiency Virus in Men Who Have Sex with Men with Herpes Simplex Virus Type 2 in the EXPLORE Study. American Journal of Epidemiology, 164, 733-741. http://dx.doi.org/10.1093/aje/kwj270

[14] Freeman, E.E., Weiss, H.A., Glynn, J.R., et al. (2006) Herpes Simplex Virus 2 Infection Increases HIV Acquisition in Men and Women: Systematic Review and Meta-Analysis of Longitudinal Studies. AIDS, 20, 73-83 http://dx.doi.org/10.1097/01.aids.0000198081.09337.a7

[15] Okuku, H.S., Sanders, E.J., Nyiro, J., Ngetsa, C., et al. (2011) Factors Associated with Herpes Simplex Virus Type 2 Incidence in a Cohort of HIV-1-Seronegative Kenyan Men and Women Reporting High-Risk Sexual Behavior. Sexually Transmitted Diseases, 38, 837-844. http://dx.doi.org/10.1093/aje/kwj270

[16] Supriya, D.M., Stephen, M., Corette, B.P., Kawango, A., Maclean, I. and Bailey, R.C. (2012) Circumcision Status and Incident Herpes Simplex Virus Type 2 Infection, Genital Ulcer Disease, and HIV Infection. AIDS, 26, 1141-1149. http://dx.doi.org/10.1097/QAD.0b013e328352d116

[17] Kissling, E., Allison, E.H., Seeley, J.A., Russell, S., Bachmann, M., Musgrave, S.D., et al. (2005) Fisherfolk Are among Groups Most at Risk of HIV: Cross-Country Analysis of Prevalence and Numbers Infected. AIDS, 19, 19391946. http://dx.doi.org/10.1097/01.aids.0000191925.54679.94

[18] Opio, A., Muyonga, M. and Mulumba, N. (2013) HIV Infection in Fishing Communities of Lake Victoria Basin of Uganda-A Cross-Sectional Sero-Behavioral Survey. PLoS ONE, 8, e70770. http://dx.doi.org/10.1371/journal.pone.0070770

[19] Kiwanuka, N., Ssetaala, A., Mpendo, J., Wambuzi, M., Nanvubya, A., Sigirenda, S., et al. (2013) High HIV-1 Prevalence, Risk Behaviours, and Willingness to Participate in HIV Vaccine Trials in Fishing Communities on Lake Victoria, Uganda. Journal of the International AIDS Society, 16, Article No. 18621. http://dx.doi.org/10.7448/IAS.16.1.18621

[20] Asiki, G., Mpendo, J., Abaasa A., Agaba1, C., Nanvubya, A., Nielsen, L., et al. (2011) HIV and Syphilis Prevalence and Associated Risk Factors among Fishing Communities of Lake Victoria, Uganda. Sexually Transmitted Infections, 87, 511-515. http://dx.doi.org/10.1136/sti.2010.046805

[21] Kwena, Z.A., Bukusi, E.A., Ng’ayo, M.O., Buffardi, A.L., Nguti, R., et al. (2010) Prevalence and Risk Factors for Sexually Transmitted Infections in a High-Risk Occupational Group: The Case of Fishermen along Lake Victoria in Kisumu, Kenya. International Journal of STD \& AIDS, 21, 708-713. http://dx.doi.org/10.1258/ijsa.2010.010160

[22] Ng’ayo, M.O., Bukusi, E.A., Morrow, R.A., Rowhani-Rahbar, A., Obare, B.A., Friedrich, D., et al. (2008) Sexual and 
Demographic Determinants for Herpes Simplex Virus Type 2 among Fishermen along Lake Victoria, Kenya. Sexually Transmitted Infections, 84, 140-142. http://dx.doi.org/10.1136/sti.2007.028795

[23] Seeley, J., Nakiyingi-Miiro, J., Kamali, A., Mpendo, J., Asiki, G., Abaasa, A., et al. (2012) High HIV Incidence and Socio-Behavioral Risk Patterns in Fishing Communities on the Shores of Lake Victoria, Uganda. Sexually Transmitted Disease, 39, 433-439. http://dx.doi.org/10.1097/OLQ.0b013e318251555d

[24] Chohan, V., Jared. M., Baeten, J.M., Benkie, S., Graham, S.M., et al. (2009) A Prospective Study of Risk Factors for Herpes Simplex Virus Type 2 Acquisition among High-Risk HIV-1 Seronegative Kenyan Women. Sexually Transmitted Infections, 85, 489-492. http://dx.doi.org/10.1136/sti.2009.036103

[25] Kenya AIDS Indicator Survey (KAIS) (2007) Preliminary Report. Kenya Ministry of Health; Nairobi, Kenya, 2008. National AIDS and STI Control Programme.

[26] Mugo, N., Dadabhai, S.S., Bunnell, R., Williamson, J., Bennett, E., Baya, I., et al. (2011) Prevalence of Herpes Simplex Virus Type 2 Infection, Human Immunodeficiency Virus/Herpes Simplex Virus Type 2 Coinfection, and Associated Risk Factors in a National, Population-Based Survey in Kenya. Sexually Transmitted Diseases, 38, 1059-1066. http://dx.doi.org/10.1097/OLQ.0b013e31822e60b6

[27] Meque, I., Dubé, K., Feldblum, P.J., Clements, A.C.A., Zango, A., et al. (2014) Prevalence, Incidence and Determinants of Herpes Simplex Virus Type 2 Infection among HIV-Seronegative Women at High-Risk of HIV Infection: A Prospective Study in Beira, Mozambique. PLoS ONE, 9, e89705. http://dx.doi.org/10.1371/journal.pone.0089705

[28] Wang, H., Reilly, K.H., Smith, M.K., Brown, K., Jin, X., Xu, J., et al. (2013) Herpes Simplex Virus Type 2 Incidence and Associated Risk Factors among Female Sex Workers in a High HIV-Prevalence Area of China. International Journal of STD \& AIDS, 24, 441-446. http://dx.doi.org/10.1177/0956462412472800

[29] Aaron, A.R.T., Charvat, B., Ssempijja, V., Kigozi, G., Serwadda, D., et al. (2009) Factors Associated with the Prevalence and Incidence of Herpes Simplex Virus Type 2 Infection among Men in Rakai, Uganda. The Journal of Infectious Diseases, 199, 945-949. http://dx.doi.org/10.1086/597074

[30] Sudenga, S.L., Kempf, M.C., McGwin, G., Wilson, C., Hook, E.W. and Shrestha, S. (2012) Incidence, Prevalence and Epidemiology of Herpes Simplex Virus-2 in HIV-1-Positive and HIV-1-Negative Adolescents. Sexually Transmitted Diseases, 39, 300-305. http://dx.doi.org/10.1097/OLQ.0b013e318244a90f

[31] Sutcliffe, C.G., Aramrattana, A., Sherman, S.G., Sirirojn, B., German, D., Wongworapat, K., et al. (2009) Incidence of HIV and Sexually Transmitted Infections and Risk Factors for Acquisition among Young Methamphetamine Users in Northern Thailand. Sexually Transmitted Diseases, 36, 284-289. http://dx.doi.org/10.1097/OLQ.0b013e318191ba17

[32] Chin-Hong, P,V., Husnik, M., Cranston, R.D., Colfax, G., Buchbinder, S., et al. (2009) Anal Human Papillomavirus Infection Is Associated with HIV Acquisition in Men Who Have Sex with Men. AIDS, 23, 1135-1142. http://dx.doi.org/10.1097/QAD.0b013e32832b4449

[33] Smith, J.S., Moses, S., Hudgens, M., Parker, C.B., Agot, K., Maclean, I., et al. (2010) Increased Risk of HIV Acquisition among Kenyan Men with Human Papillomavirus Infection. The Journal of Infectious Diseases, 201, 1677-1685. http://dx.doi.org/10.1086/652408

[34] Averbach, S.H., Gravitt, P.E., Nowak, R.G., Celentano, D., Dunbar, M., Morrison, C., et al. (2010) The Association between Cervical Human Papillomavirus Infection and HIV Acquisition among Women in Zimbabwe. Aids, 24, 10351042. http://dx.doi.org/10.1097/QAD.0b013e3283377973

[35] Lissouba, P., Van de Perre, P. and Auvert, B. (2013) Association of Genital Human Papillomavirus Infection with HIV Acquisition: A Systematic Review and Meta-Analysis. Sexually Transmitted Infections, 89, 350-356. http://dx.doi.org/10.1136/sextrans-2011-050346

[36] Veldhuijzen, N.J., Snijders, P.J., Reiss, P., Meijer, C.J.L.M. and van de Wijgert, J.H.H.M. (2010) Factors Affecting Transmission of Mucosal Human Papillomavirus. The Lancet Infectious Diseases, 10, 862-874. http://dx.doi.org/10.1016/S1473-3099(10)70190-0

[37] Mbopi-Keou, F.X., Robinson, N.J., Mayaud, P., Belec, L. and Brown, D.W.G. (2003) Herpes Simplex Virus Type 2 and Heterosexual Spread of Human Immunodeficiency Virus Infection in Developing Countries: Hypotheses and Research Priorities. Clinical Microbiology and Infection, 9, 161-171. http://dx.doi.org/10.1046/j.1469-0691.2003.00550.x

[38] Ramjee, G., Williams, B., Gouws, E., Van Dyck, E., Deken, B. and Karim, S.A. (2005) The Impact of Incident and Prevalent Herpes Simplex Virus-2 Infection on the Incidence of HIV-1 Infection among Commercial Sex Workers in South Africa. JAIDS Journal of Acquired Immune Deficiency Syndromes, 39, 333-339.

http://dx.doi.org/10.1097/01.qai.0000144445.44518.ea 